\title{
METODOLOGIAS ATIVAS E O USO DO FACEBOOK COMO INTERFACE COLABORATIVA NA EDUCAÇÃO SUPERIOR
}

\author{
ACTIVE METHODOLOGIES AND THE USE OF FACEBOOK AS A COLLABORATIVE \\ INTERFACE IN HIGHER EDUCATION
}

\section{METODOLOGÍAS ACTIVAS Y EL USO DEL FACEBOOK COMO INTERFAZ COLABORATIVA EN LA EDUCACIÓN SUPERIOR}

Maria Paula Mansur Mäder

E-mail: mpmader@gmail.com

Marilda Aparecida Behrens

E-mail: marildaab@gmail.com

Programa de Pós-Graduação em Educação da Pontifícia Universidade Católica do Paraná - PUCPR

\section{RESUMO}

Este artigo apresenta observações e reflexões sobre a aplicação do Facebook como recurso de ensino-aprendizagem, considerando-o um suporte para promover aproximação e interação dos estudantes, numa turma de 26 alunos de uma disciplina específica de um curso superior de uma instituição privada de Curitiba. Caracteriza-se tal pesquisa como um procedimento de pesquisa-ação, de abordagem qualitativa que partiu de uma experiência empírica. A fim de proporcionar meios de aprendizagem mais acessíveis e próximos ao perfil dos alunos, todos da geração $\mathrm{Y}$, foi criado pela professora um grupo fechado no Facebook, no qual foi promovida a interação dos alunos com o objetivo de verificar a aceitação e engajamento por meio de uma mídia social, no que diz respeito ao seu uso como recurso educacional. Coube ainda uma reflexão sobre a formação docente numa visão complexa para atuar nesse contexto e apreciação da ubiquidade como um desafio já instalado na realidade da educação.

PALAVRAS-CHAVE: Redes sociais. Formação docente. Ensino Superior.

\section{ABSTRACT}

This paper presents observations and reflections about the application of Facebook as a teaching and learning tool, considering it a support to promote connection and interaction of the students, in a group of 26 undergraduate students enrolled in a course of a private higher institution in Curitiba. This research is characterized as action research with a qualitative approach that arose from an empirical experience. In order to provide means of learning more accessible and near to the students profile, all from the Y generation, a closed group was created by the teacher in Facebook, where the interaction of students was encouraged, with the aiming of ensuring the acceptance and commitment using social media, in what concerns its use as an educational tool. A reflection follows, with a complexity vision about the teacher training for acting in this context, and the appreciation of ubiquity as a challenge already installed in the reality of education.

KEYWORDS: Social networks. Teacher training. Higher education.

\section{RESUMEN}

Este artículo presenta observaciones y reflexiones sobre la aplicación de Facebook como recurso de enseñanzaaprendizaje, considerándolo un soporte para promover acercamiento e interacción de los estudiantes, en una clase de 26 alumnos de una disciplina especifica de un curso superior de una institución privada de Curitiba. Se caracteriza tal investigación como un procedimiento de investigación-acción, de abordaje cualitativo que partió de una experiencia empirica. A fin de proporcionar medios de aprendizaje más accesibles y próximos al perfil de los alumnos, todos de la generación Y, fue creado por la profesora un grupo cerrado en Facebook, en el cual se promovió la interacción de los alumnos con el objetivo de verificar la aceptación y compromiso por medio de un medio social, en lo que se refiere a su uso como recurso educativo. Además, una reflexión sobre la formación docente en una visión compleja para actuar en ese contexto y apreciación de la ubicuidad como un desafio ya instalado en la realidad de la educación.

PALABRAS-CLAVE: Redes sociales. Formación docente. Enseñanza superior. 


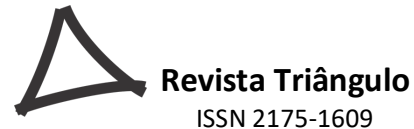

ISSN 2175-1609

\section{INTRODUÇÃO}

Dentre os muitos desafios com os quais nos deparamos ao propor novos caminhos para o processo de ensino-aprendizagem, chama-nos a atenção a rápida evolução das tecnologias digitais de informação e comunicação (TDICs) que estão presentes na sociedade em todas as suas dimensões. O acesso a diversos conteúdos de forma democrática mudou por completo a forma com que as pessoas buscam informações, e também, como aprendem.

Há mais de um século, John Dewey (apud VALENTE, 2014) já criticava o processo de ensinoaprendizagem baseado na transmissão de informação, apresentando sua proposta de aprendizagem baseada no fazer e argumentando que as aulas expositivas partem do pressuposto de que todos os estudantes aprendem no mesmo ritmo e absorvendo informações somente ouvindo o professor, o que já se sabe hoje ser um equívoco.

Nesse já não tão novo contexto tecnológico, os docentes estão atuando diante de um novo perfil de alunos, as gerações chamadas $\mathrm{Y}$ e Z, que se relacionam intimamente com as tecnologias e através delas. Conforme Gabriel (2013), cada vez mais cedo os jovens têm acesso às tecnologias e por conta disso há cada vez mais jovens operando mudanças significativas no universo. O ritmo das transformações hoje é muito diferente, mais rápido, do que há 3 décadas, o que faz com que pessoas com mais de 35 anos precisem se adaptar rapidamente, enquanto que aqueles com menos de 20 anos são nativos e, em geral, muito ágeis neste cenário digital.

No cenário educacional, isso representa uma necessidade urgente de mudanças paradigmáticas, pois de modo geral os profissionais dessa área ainda são da geração X (ou geração analógica, nascidos entre 1960 e início de 1980). Para que os processos educacionais possam ultrapassar as barreiras de conflito entre as gerações, faz-se necessário que esses educadores tomem conhecimento, antes de mais nada, das características dessas gerações, de seus interesses e de seus principais equipamentos de comunicação e de acesso à informação, bem como entender a forma como se relacionam e especialmente como aprendem.

Consideremos, para tanto, que existem três formas diferentes de ensino-aprendizagem, que se mesclam na formação dos sujeitos: a educação escolar, de caráter formal, desenvolvida na escola; a educação informal, adquirida por meio da convivência social com a família, os amigos, nos clubes e até mesmo no teatro e por meio da literatura; e por fim a educação não-formal, que se dá justamente quando há intenção do sujeito em buscar aprendizagem fora de seu contexto escolar. A partir da reflexão proposta por Santaella (2010), a educação não-formal caracteriza-se por uma aprendizagem

\begin{tabular}{|c|c|c|c|c|c|}
\hline (C) Revista Triângulo & Uberaba, Minas Gerais & v.12 & n.2 & p. $101-116$ & 2019 \\
\hline
\end{tabular}


de caráter ubíquo, que se realiza graças à evolução proporcionada pelas tecnologias comunicacionais, a saber: a tecnologia do livro; a educação a distância; a aprendizagem em ambientes virtuais e, por fim, a aprendizagem por meio de dispositivos móveis, que promovem tal ubiquidade da aprendizagem.

De acordo com Santos e Weber (2013), a mobilidade vem acompanhando a humanidade desde as civilizações nômades, com o surgimento das cidades e o desenvolvimento urbano, nas quais se pode perceber outras temporalidades, especialmente na dimensão comunicacional, que com o surgimento dos dispositivos móveis, intensificam ainda mais essa mobilidade. Para Lemos (apud Santos e Weber, 2013), existem três dimensões da mobilidade: a física, que se refere aos objetos; a do pensamento, passível de deslocamentos; e a informacional-virtual, que é justamente a dimensão que faz circular a informação em rede. A partir de tais dimensões, Santaella (2010) propõe a existência de espaços criados chamados intersticiais, que misturam os espaços físicos e o ciberespaço, a partir do uso de dispositivos móveis, levando à compreensão de que a ubiquidade representa uma habilidade de comunicação a qualquer tempo, em qualquer hora, utilizando dispositivos móveis, que estejam conectados a redes sem fio.

Para Jones e Jo (2004), um ambiente de aprendizagem ubíquo é onipresente, ou seja, o aluno está imerso nele e a educação acontece ao seu redor, e esse aluno pode nem sequer estar consciente do processo de aprendizagem, já que as informações estão incorporadas ao seu cotidiano.

A ubiquitous learning environment is any setting in which students can become totally immersed in the learning process. To define: Ubiquitous = pervasive, omnipresent, ever present, everywhere; Learning = educational, instructive, didactic, pedagogical; Environment = surroundings, setting, situation, atmosphere. So, a ubiquitous learning environment (ULE) is a situation or setting of pervasive (or omnipresent) education (or learning). Education is happening all around the student but the student may not even be conscious of the learning process. Source data is present in the embedded objects and students do not have to DO anything in order to learn. They just have to be there. ${ }^{1}$

A partir dessa referência, este artigo se propõe a apresentar uma reflexão, que teve como ponto de partida a observação da aplicação prática do uso do Facebook, por parte da autora, como

\footnotetext{
1 Um ambiente de aprendizagem onipresente é qualquer ambiente em que os alunos podem ficar totalmente imersos no processo de aprendizagem. Definir: Onipresente = onipresente, onipresente, sempre presente, em todos os lugares; Aprendizagem = educativa, instrutiva, didática, pedagógica; Meio ambiente = ambiente, cenário, situação, atmosfera. Assim, um ambiente de aprendizado onipresente (ULE) é uma situação ou cenário de educação difundida (ou onipresente) (ou aprendizagem). A educação está acontecendo em todo o aluno, mas o aluno pode nem estar consciente do processo de aprendizagem. Os dados de origem estão presentes nos objetos incorporados e os alunos não precisam fazer nada para aprender. Eles só precisam estar lá.
}

\begin{tabular}{l|l|l|l|l|l|} 
(C) Revista Triângulo & Uberaba, Minas Gerais & v.12 & n.2 & p. $101-116$ & 2019
\end{tabular}


ferramenta de aproximação e interação com alunos de uma disciplina específica de um curso superior de uma instituição privada de Curitiba. Caracteriza-se tal pesquisa como um procedimento de pesquisa-ação, de abordagem qualitativa que partiu de uma experiência empírica. A fim de proporcionar meios de aprendizagem mais acessíveis e próximos ao perfil dos alunos, todos da geração Y, foi criado pela professora um grupo fechado no Facebook, no qual foram postados materiais complementares aos conteúdos ministrados em sala, links direcionando para matérias de sites e para vídeos sobre temáticas relativas à área, para os quais foram solicitados comentários aos participantes, e ainda o espaço do grupo serviu para a postagem dos trabalhos realizados pelos alunos durante o semestre, oportunizando um fórum de apreciação dos mesmos pelos colegas da turma. Essa mescla de recursos aproxima a proposta ao conceito de blended learning, pois apesar de estar alicerçada no ensino presencial, apropria-se da complementaridade promovida entre atividades realizadas em sala de aula e outras realizadas on-line. Os autores Staker e Horn (apud Valente, 2014, p. 84.)

[...] definem blended learning como um programa de educação formal que mescla momentos em que o aluno estuda os conteúdos e instruções usando recursos on-line, e outros em que o ensino ocorre em uma sala de aula, podendo interagir com outros alunos e com o professor. Na parte realizada on-line o aluno dispõe de meios para controlar quando, onde, como e com quem vai estudar. Esses autores enfatizam o aspecto formal para diferenciar as situações de aprendizagem que acontecem informalmente $[\ldots]$

Também podendo ser denominado ensino híbrido, como é reconhecido no Brasil, tal modalidade se propõe a oferecer aos alunos "o melhor de dois mundos", mesclando momentos presenciais - que não necessariamente acontecem na sala de aula tradicional - com atividades desenvolvidas fora do contexto escolar, geralmente utilizando-se de TDICs, seja para acessar as propostas de atividades, seja para compartilhar seus resultados com o professor e/ou os colegas, ou até mesmo para desenvolver a atividade em si.

Conforme elucida Moran (2015, p. 45), "Falar em educação híbrida significa partir do pressuposto de que não há uma única forma de aprender e, por consequência, não há uma única forma de ensinar. Existem diferentes maneiras de aprender e ensinar.", o que respalda a proposta descrita neste artigo, que se propõe a oportunizar aos alunos uma forma diferente de aprender e especialmente experienciar o seu aprendizado. 


\section{A FORMAÇÃO DO PROFESSOR PARA UM NOVO CONTEXTO}

A formação do professor precisa ser revista, a fim de obter os melhores resultados educacionais por meio das práticas mediadas pela tecnologia. Porém, cabe destacar que a tecnologia por si representa um mero instrumental, e que sua relevância reside no potencial que traz às metodologias de ensino, mas a grande mudança a qual nos referimos diz respeito ao paradigma da complexidade (MORIN, 2000, 2001, 2009), que vem trazer um novo olhar para a educação, voltandose a uma formação contextualizada, em que os alunos sejam instigados a pesquisar e crescer a partir de suas próprias descobertas, e que esse aprendizado seja significativo para sua vida.

Atender à necessidade de uma mudança paradigmática com visão complexa implica em optar por metodologias ativas que acolham aprendizagem colaborativa. Trata-se de abandonar a forma fragmentada com que ainda se ensina em prol de metodologias que propiciem uma transdisciplinaridade, princípio este intrínseco à teoria da complexidade, já que ambos "surgem em decorrência do avanço do conhecimento e do desafio que a globalidade coloca para o século XXI", conforme afirma Santos (2009, p. 15).

Em termos conceituais, as metodologias ativas correspondem, justamente, a uma proposta de ensino que percebe o aluno como centro do processo de ensino-aprendizagem, e nesses termos ele passa de sujeito passivo, ou mero receptor de informações, para um papel de sujeito ativo, protagonista na sua construção do conhecimento, que passa então a acontecer de forma contextualizada e significativa, entendendo que, conforme menciona Behrens (2013, p. 55) esse papel autônomo, criativo e crítico provoca no aluno uma interpretação do conhecimento, e não apenas sua aceitação, e o papel do professor é conduzir esse processo a fim de tornar o aluno sujeito e produtor de seu próprio conhecimento.

Não é apenas pelo desafio de propor uma metodologia ativa inovadora, mas considerar a possibilidade de usufruir de diferentes recursos, com destaque neste relato para o suporte de uma rede social mas, acima de tudo, trata-se da urgência em rever a postura docente frente ao indivíduo em formação, tirando proveito dos recursos tecnológicos disponíveis, associados a uma prática pedagógica capaz de conduzir o aluno ao melhor resultado de aprendizagem. Não se trata de meramente impor ao docente a utilização de um aparato tecnológico, já que, conforme afirma Valente (2005, p. 30): 
A formação do professor envolve muito mais do que provê-lo com conhecimento técnico sobre computadores. Ela deve criar condições para que ele possa construir conhecimento sobre os aspectos computacionais, compreender as perspectivas educacionais subjacentes às diferentes aplicações do computador e entender por que e como integrar o computador na sua prática pedagógica. Deve proporcionar ao professor as bases para que possa superar barreiras de ordem administrativa e pedagógica, possibilitando a transição de um sistema fragmentado de ensino para uma abordagem integradora de conteúdo e voltada para a elaboração de projetos temáticos do interesse de cada aluno. Finalmente, deve criar condições para que o professor saiba recontextualizar o aprendizado e a experiência vivida durante sua formação para sua realidade de sala de aula, compatibilizando.

Complementando essa reflexão, é interessante a afirmação de Valente (apud MODESTO, 2011) quando propõe que ainda há dois tipos de professores atuando nesse contexto: os deslumbrados com a tecnologia e os céticos. Esses perfis destacam claramente a emergência da reflexão e de propostas efetivas para a formação dos docentes, já que ambos esses dois tipos citados denotam a fragilidade em atuar frente às novas tecnologias, e mais ainda de atingir os objetivos de aprendizagem por meio delas. Ainda o ceticismo, presente em diversos contextos educacionais, distancia a passos largos o docente de seus alunos, dificultando a aprendizagem e criando nesses alunos uma postura até mesmo refratária, já que este professor não transita no ambiente em que se encontram as informações.

Sobre esse fator, Mattar (apud MODESTO, 2011) destaca o papel do educador no cenário virtual remetendo às suas experiências com EAD e ambientes virtuais de aprendizagem (AVAs), afirmando que o docente tem um importante papel, já que é ele que deve criar conteúdos que privilegiem a interação e vai definir os critérios pedagógicos para que ela ocorra, no que Valente (apud MODESTO, 2011) concorda e ainda reforça, considerando o fato de que sem a mediação docente, as tecnologias, e especialmente o uso das redes sociais não representarão seu caráter educativo: "Vemos que os bons casos de utilização das mídias sociais são aqueles em que o educador acompanha todo o processo, utiliza as ferramentas tendo em vista um projeto pedagógico mais amplo e demonstra domínio das funcionalidades que o meio escolhido possui." (VALENTE, apud MODESTO, 2011)

Para a necessidade da educação formal, Santaella (2013) chama a atenção sobre o aprender a conviver com estratégias de complementaridade, relacionadas a aprendizagem ubíqua. Dentro ou fora de uma sala de aula, o aluno pode saciar uma curiosidade apenas acessando o seu celular conectado à rede, independente da presença do professor, e ainda pode fazer isso por meio de uma rede social, o que caracteriza a troca, a colaboração entre amigos ou pessoas de interesse comum. Por outro lado,

\begin{tabular}{|l|l|l|l|l|l|} 
(C) Revista Triângulo & Uberaba, Minas Gerais & v.12 & n.2 & p. $101-116$ & 2019
\end{tabular}


a mesma autora destaca que essa aprendizagem ubíqua não substitui as sistemáticas de aprendizagem formal, mas sim que deve ser somada a elas. Reside nessa prática mais um desafio ao docente, para incorporar o uso dessas tecnologias de forma crítica e competente, de acordo com Moraes (2010).

\section{O FACEBOOK COMO PLATAFORMA DE ENSINO}

O Facebook é um site que oferece a seus usuários um serviço de rede social, criada por quatro estudantes de Harvard e lançada em fevereiro de 2004. Desde então vem crescendo a cada ano, tendo atingido a marca de 1,59 milhão de usuários no mundo, no final de 2015. O objetivo inicial do site era ajudar universitários a trocarem informações e se conhecerem no grande campus da instituição, mas a receptividade foi tão grande que em pouco tempo já havia atingido outras instituições e até mesmo escolas do ensino médio, ganhando o mundo. ${ }^{2}$

Conforme explicitam Ferreira et al (2011, p. 8 apud TSUKAMOTO et al, 2015, p. 353), o Facebook é:

[...] uma das redes sociais mais utilizadas em todo o mundo para interagir socialmente. Esta interação surge essencialmente pelos comentários a perfis, pela participação em grupos de discussão ou pelo uso de aplicativos e jogos. É um espaço de encontro, partilha, discussão de ideias e, provavelmente, o mais utilizado entre os estudantes universitários.

Dessa forma, destaca-se o potencial da rede social, que pode ser explorado como ferramenta para o ensino às novas gerações de estudantes, já que esses estão presentes nessa rede, e possuem intimidade com o ambiente e suas ferramentas. A interatividade proporcionada pelo site incrementa o processo de ensino-aprendizagem e provoca o estudante a abandonar seu papel passivo e a interagir com o professor e os colegas através de postagens e comentários no grupo proposto.

De acordo com Mattar (apud Modesto, 2011), as redes sociais podem ser divididas em três grupos: no $1^{\circ}$ grupo ele coloca as mais famosas, como por exemplo o Facebook, pois elas têm ampla penetração na sociedade, apesar de apresentarem poucos recursos educacionais; o $2^{\circ}$ grupo engloba ferramentas que, além de sua função de rede social também disponibilizam conteúdos aos usuários, como é o caso do YouTube, do Twitter, do Flickr, e esses são os que apresentam mais resultados

2 FACEBOOK. In: WIKIPÉDIA, a enciclopédia livre. Flórida: Wikimedia Foundation, 2017. Disponível em: <https://pt.wikipedia.org/w/index.php?title=Facebook\&oldid=48099654>. Acesso em: 24 fev. 2017. 
positivos para a educação; e por último o $3^{\circ}$ grupo, mais amplo, que considera a rede social como qualquer grupo que se organiza e se relaciona, e esses pouco vão acrescentar para a educação.

Cabe sempre lembrar que, ao nos depararmos com o atual cenário, denominado então revolução digital, não é a tecnologia em si que se torna importante, mas sim devemos voltar nosso olhar para a sua utilidade, especialmente em prol de melhorias para a sociedade. No aspecto educacional, a tecnologia vem trazer novos desafios aos docentes, tornando o papel do professor como o único provedor de conhecimento um conceito ultrapassado, assim como acreditar que o livro, especialmente em sua versão impressa em papel, ainda seja capaz de se configurar como a única fonte segura e completa de consulta à informação.

Nesse sentido, "Quando novas informações surgem e as circunstâncias mudam, já não é possível resolver os problemas com as soluções de ontem”, afirma Oech (1998, apud GABRIEL, 2013, p. 7). Assim, o mercado e especialmente as instituições de ensino necessitam voltar seu olhar para uma formação digital, que deve ter início na formação daqueles que interagem com a geração de nativos digitais, ou seja, falamos novamente aqui de uma formação adequada dos professores, para que esses possam tirar proveito das tecnologias para o ensino.

A banda larga de internet representa um dos fatos principais que permitiu a configuração da sociedade conforme nos deparamos, ou seja, conforme destaca Gabriel (2013), ela estabelece uma diferença entre o status de "estar conectado" e "ser conectado", justificando a diferença entre a geração que utilizava a internet na década de 1990, com conexões discadas, permitindo entrar e sair da rede, e a geração de hoje, que vive em plena simbiose com a rede, conectada o tempo inteiro.

A partir desse novo status, cresce exponencialmente o acesso a todo tipo de informação, transformando completamente o papel do docente no processo de ensino-aprendizagem. E as redes sociais, como por exemplo o Facebook, proporcionam ampla possibilidade de produção e disseminação de todo tipo de conteúdo na rede, incluindo os conteúdos de caráter educacional. Por outro lado, nesse ambiente da rede social, há completa descentralização e abandono da hierarquia na produção e disseminação do conhecimento, o que evidencia mais uma vez o caráter social da rede.

A reprodução abaixo, inspirada em Gabriel (2013, p. 16) busca ilustrar essa diferença promovida pela ubiquidade da informação na era digital, alterando o papel do professor como filtro de conteúdo. Há que se considerar que esse poder de produção e consumo da informação transforma a educação, pois o domínio e a gestão da informação/conteúdo passam a estar disponível para qualquer pessoa em qualquer lugar do mundo. 
Figura 1 Esquema de acesso à informação na era pré-digital e na era digital

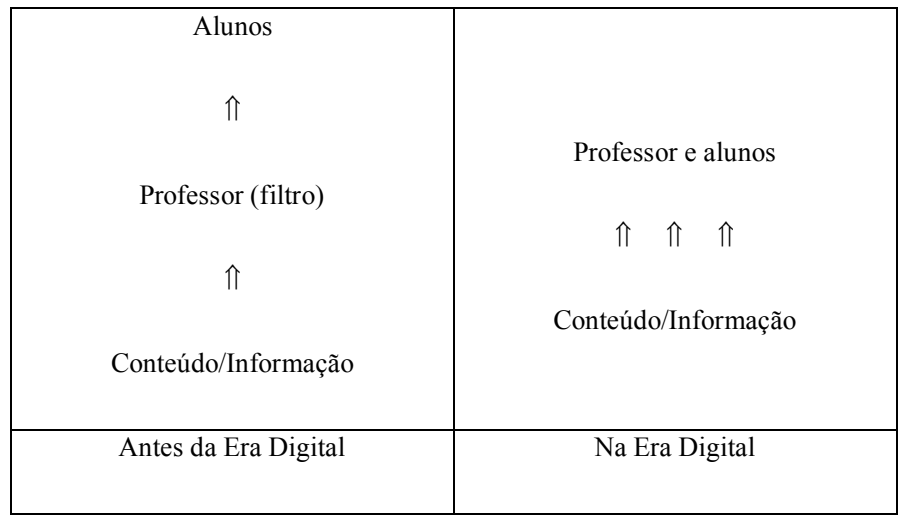

Fonte: GABRIEL, 2013, p. 16.

A ideia de hiperconexão por meio das redes sociais traz consigo uma significativa mudança em todo o processo de aquisição de informação, e claramente reflete na educação. Entende-se hiperconexão como sendo a possibilidade gerada pela mobilidade para estabelecer diferentes tipos de conexão, em diferentes locais e a partir de qualquer local; trata-se de conexão entre pessoas, mas também entre pessoas e máquinas e até mesmo entre máquinas.

Não há como ignorar que o processo de aprendizagem se dá hoje, em grande parte, fora da sala de aula, e até mesmo fora do próprio ambiente escolar. Por conseguinte, o já referido papel de filtro exercido pelo professor, deixa de ser importante, e a busca na rede passa a ser motivada pelo interesse do aluno, e o desafio agora é promover esse interesse, que só será alcançado pelo docente que direcionar o seu foco para o aluno, e por isso "os conteúdos educacionais precisam ser repensados em função da participação e do interesse dos alunos de forma a constituir um processo de troca e não mais de mão única.” (GABRIEL, 2013, p. 33).

Estamos diante de um cenário de ubiquidade, que atinge também a educação. Essa conexão contínua, o "estar conectado", promove o que Santaella (2013) chama de aprendizagem ubíqua, justamente por possibilitar novas formas de aprendizagem mediadas especialmente pelos dispositivos móveis, possibilitando a interação de seus interlocutores em qualquer local, a partir de qualquer dispositivo, a qualquer momento, e como consequência o aprendizado formal se mescla ao dia a dia, misturando a cultura e a vivência e eliminando as barreiras da sala de aula.

Retomamos, então, a proposta de utilização da rede social Facebook, que por seu caráter social e sua possibilidade de acesso a partir de qualquer dispositivo conectado, propicia um contato permanente do estudante com o conteúdo, por meio de grupos de interação, promovendo trocas e 
consequentemente uma aprendizagem também colaborativa. Por meio da plataforma virtual, professor e alunos podem compartilhar diversos recursos (textos, imagens, vídeos, links etc.) e dessa forma ambos ampliam e desenvolvem seus conhecimentos. Nesse papel, o professor deixa de ser o centro difusor para fazer parte de um grupo de trocas, devendo incentivar e direcionar o processo.

Conforme destacam Ebeling e Bohada (2013), há nesse contexto uma questão crucial, que é a participação ativa do aluno no processo de produção do conhecimento, entendendo a partir das teorias de construtivismo de Piaget e de sociointeracionismo de Vygotsky que a aprendizagem se dá de maneira mais fácil e significativa quando advém de um processo de interação e colaboração.

Mas o que leva o indivíduo a aprender? Realizar atividades de colaboração e interação; confrontar-se com conteúdos que lhe sejam significativos, próximos, relacionados ao seu contexto de vida; ser acolhido pelo grupo de interesse; ter feedback de incentivo do professor; pelo prazer, porque gosta de um assunto, de uma mídia, de uma pessoa (MORAN, 2000 apud EBELING, BOHADA, 2013, p. 304).

A possibilidade de interação virtual traz consigo alguns outros elementos que devem ser também considerados, como a espontaneidade por parte dos interlocutores, já que as participações acontecem no tempo e no espaço que eles determinam, sem a pressão do imediatismo de uma pergunta feita pelo professor em sala de aula; a desinibição, pois uma vez distante fisicamente, esse interlocutor se sente menos inibido para cometer erros; e por último, uma competitividade saudável, já que muitos fazem questão de postar a fim de demonstrar seu conhecimento ou sua pesquisa sobre o tema suscitado.

\section{METODOLOGIA E RELATO DE CASO ESTUDADO}

A proposição de considerar a visão complexa e optar por uma metodologia ativa levou a realizar uma pesquisa-ação que possibilitou a vivência de produção de conhecimento dos alunos por meio da utilização do Facebook. Conforme Vergara (2007), aplica-se a estratégia da pesquisa-ação quando se tem como objetivo buscar soluções para problemas através de ações definidas por pesquisadores e sujeitos envolvidos na situação investigada, tornando-se, portanto, o pesquisador também participante/atuante. A metodologia de pesquisa-ação acaba por aproximar os procedimentos da investigação com as atividades práticas e/ou empíricas de aplicação de conhecimentos, servindose para reunir os objetivos de uma investigação de caráter científico a uma aplicação prática para solucionar um problema. 
Essa vivência metodológica ocorreu em uma turma de 26 alunos do curso de Publicidade e Propaganda, na disciplina de Redação Publicitária. Trata-se de uma disciplina de caráter teóricoprático, com carga horária de $80 \mathrm{~h} / \mathrm{a}$ no semestre, ministradas em 2 encontros semanais de $2 \mathrm{~h} / \mathrm{a}$ cada. Para tanto, foi criado no ambiente do Facebook um grupo fechado, no qual todos os alunos foram incluídos e poderiam postar materiais a sua escolha no grupo, desde que pertinentes ao conteúdo ministrado.

A primeira atividade investigativa proposta aos alunos, que transcendeu a sala de aula e explorou o espaço da rede, foi a postagem do resultado de um trabalho de criação de uma mensagem publicitária, que teve início em sala de aula e foi finalizado posteriormente pelos alunos, devendo o resultado ser postado no grupo. Assim que as equipes postaram seus trabalhos, a professora procedeu com os comentários sobre a atividade nas postagens de cada um deles. A forma de feedback agradou aos alunos, que participaram ativamente da discussão respondendo e questionando as observações da professora, fato que em geral não ocorre quando o feedback é dado em sala de aula, junto ao grande grupo.

A segunda atividade investigativa proposta foi que, a partir de um tema apresentado em sala de aula pela professora, que envolvia um tipo específico de campanha publicitária, os alunos deveriam pesquisar exemplos para postar no grupo, com o objetivo de ampliar a gama de exemplos para os colegas. O resultado foi uma "disputa" entre os alunos a fim de postar a campanha mais original, que ninguém ainda conhecesse, o que resultou em ampla busca por parte dos alunos e muitos comentários entre eles nas postagens de cada colega, sobre o exemplo disponibilizado.

Uma terceira atividade investigativa foi desenvolvida a partir da postagem, pela professora, de um link para uma matéria publicada em veículo especializado na área, que trazia a temática abordada em sala. Foi solicitado aos alunos a leitura e postagem posterior de comentários que respondessem a alguns tópicos indicados pela professora, referentes ao conteúdo ministrado em sala de aula.

A quarta atividade investigativa consistiu em solicitar aos alunos a análise de uma peça publicitária, de acordo com alguns critérios previamente indicados, e que tal análise fosse postada no grupo para apreciação dos colegas, que deveriam se manifestar sobre os comentários dos autores.

Além das atividades propostas e direcionadas, o espaço se tornou um repositório de conteúdos complementares às aulas por parte da professora, e ainda promoveu aos alunos a chance de 


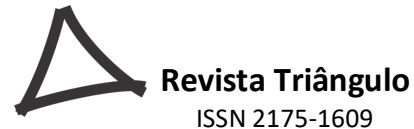

ISSN 2175-1609

compartilhar com os colegas diversos links para conteúdos que os mesmos encontraram na rede e consideraram interessantes para a disciplina. A interação promovida na rede social teve reflexos muito relevantes na sala de aula, pois foi possível observar que a partir de participação dos alunos de forma virtual, os mesmos passaram a se sentir "parte responsável" pelo conteúdo e pelas atividades desenvolvidas na disciplina de forma presencial.

Ao final do semestre, foi aberto pela professora, por meio do próprio grupo do Facebook, um fórum para as manifestações dos alunos sobre o uso da rede social na disciplina. Foram lançadas as seguintes perguntas para direcionar os comentários: 1)Você considera positivo ou negativo ou uso do Facebook como espaço virtual complementar para a disciplina? 2)Você julga que suas participações aumentaram com a possibilidade de fazê-las pelo grupo da rede? 3) Você considera que os conteúdos compartilhados no grupo auxiliaram no rendimento da disciplina como um todo? 4) Comente o que você mais gostou e o que menos gostou no uso do Facebook na disciplina.

O resultado observado por meio das respostas dos alunos é que $100 \%$ se manifestaram positivamente em relação ao uso da ferramenta, em comentários como: "Usar o Facebook é muito mais acessível do que usar o Portal do Aluno", ou ainda "Pelo Facebook fica mais fácil de ter acesso aos conteúdos, e ao que tá 'rolando' na aula.'. Quanto a se sentirem mais motivados e menos intimidados para compartilhar comentários e mesmo para receber as críticas sobre seus trabalhos através da rede, apenas um aluno comentou que: "Não me sinto a vontade para criticar os trabalhos dos meus colegas, mesmo no grupo". A possibilidade de ter os conteúdos complementares disponíveis no grupo também foi elogiado por $100 \%$ do grupo, e foi destacado por grande parte deles a facilidade de interagir por meio de uma rede com a qual eles já estão familiarizados e estão sempre conectados: “É bom saber que os conteúdos das aulas estão acessíveis pra gente no grupo, fica mais fácil pra estudar e consultar quando precisa.” Não houve manifestações de fato negativas em relação ao uso da ferramenta.

A experiência se mostrou positiva e produtiva, o que resultou em novas aplicações regulares pela docente em outras disciplinas que leciona no curso, obtendo resultados excelentes no processo de ensino aprendizagem. A cada nova turma, nota-se mais engajamento e autonomia por parte dos alunos; instigar a pesquisa autônoma, ou mesmo em duplas de trabalho, promove implicitamente um contexto dos conteúdos para os alunos, já que os desafios propostos se mostram como oportunidades para eles demonstrarem, tanto para a professora como para os colegas, os seus potenciais 
conhecimentos. Nesse sentido, refletem Bacich e Moran (2018) sobre o sentido da escola ou da universidade:

Para os estudantes de hoje, qual é o sentido da escola ou da universidade diante da facilidade de acesso à informação, da participação em redes com pessoas com as quais partilham interesses, práticas, conhecimentos e valores, sem limitações espaciais, temporais e institucionais, bem como diante da possibilidade de trocar ideias e desenvolver pesquisas colaborativas com especialistas de todas as partes do mundo?

E, portanto, por meio dessa metodologia, oportuniza-se ao aluno uma ampla possibilidade de pesquisa e de troca, tanto na grande rede quanto no grupo, entre os colegas, cabendo assim à professora o papel de curadoria dessas experiências trazidas pelos alunos, que enriquecem e atualizam constantemente os conteúdos ministrados em sala de aula, fator de grande relevância quando se trata da formação de profissionais de uma áera de atuação em mudanças permanentes.

\section{CONSIDERAÇÕES FINAIS}

Vivemos hoje um momento de diversas oportunidades de mudanças paradigmáticas, promovidas pela busca de metodologias que considerem a visão do todo, a inclusão do diferente, a produção do conhecimento, a aprendizagem ativa, colaborativa e compartilhada. Para tanto, com visão inovadora optarmos pelas TDICs, e sobretudo do ponto de vista educacional é necessário perceber que essas TDICs estão entrando em sala de aula e que os alunos se relacionam com elas - e por intermédio delas - com grande destreza, mas com qual objetivo? Para os docentes que estão preparados para explorar os recursos a favor do processo de ensino-aprendizagem, as TDICs estão se tornando aliadas cada vez mais poderosas. Por outro lado, há ainda muito docentes que se sentem desconfortáveis, e em alguns casos até mesmo céticos da utilidade das TDICs na educação. Sem dúvida há o interesse das instituições em mudar seus projetos e implantar inovações, já que esse fator representa, especialmente para as instituições privadas, uma questão de sobrevivência diante da concorrência, em que a tecnologia passa a ser o diferencial essencial do contexto atual.

Mas de nada vai adiantar a tecnologia implantada se não houver a formação adequada dos docentes, e nesse caso destacamos não apenas a formação para o uso das novas tecnologias, mas especialmente uma mudança de postura desse docente, entendendo seu papel de intermediador no processo e considerando a aprendizagem ubíqua. O grande desafio reside em formar docentes aptos a promover formas de integrar os contextos e saberes, de explorar a complementaridade que os

\begin{tabular}{l|l|l|l|l|l} 
(ㄷ) Revista Triângulo & Uberaba, Minas Gerais & v.12 & n.2 & p. 101 - 116 & 2019
\end{tabular}


diferentes processos de ensino-aprendizagem vêm proporcionar a essa nova geração. Para tanto, há que se buscar na formação do professor a adequação para atingir os objetivos por meio dessa complementaridade, convergindo os espaços físicos e virtuais a fim de oferecer aos sujeitos um processo de aprendizagem cada vez mais enriquecedor, sempre considerando que

[...] cada uma das formas de aprendizagem apresenta potenciais e limites que lhe são próprios. Por isso mesmo, a educação a distância não substitui inteiramente a educação gutenberguiana, assim como a aprendizagem em ambientes virtuais não substitui ambas, tanto quanto a aprendizagem ubíqua não é capaz de substituir quaisquer dessas formas anteriores. Ao contrário, todas elas se complementam, o que torna o processo educativo muito mais rico." (SANTAELLA, 2010, p. 21)

A experiência da metodologia ativa aqui relatada acolheu como recurso de aprendizagem a rede social Facebook, e com essa opção permitiu observar sua utilização no ensinar e aprender na educação superior e, ainda, possibilitou uma reflexão sobre a formação do docente para atuar nesse novo contexto. O processo investigativo permitiu evidenciar que a aprendizagem ubíqua é uma realidade, que sem dúvida desafia a educação, e para tirar o melhor proveito, há necessidade de propor metodologia ativas, que atendam a um novo paradigma contemplando uma visão complexa. Assim, conclui-se que o maior desafio recai na mudança paradigmática que atenda aos interesses dos alunos, e esta mudança depende de movimentos que se debrucem sobre a formação inicial e principalmente a formação continuada do professor.

\section{REFERÊNCIAS}

BACICH, L.; MORAN, J. M. Aprender e ensinar com foco na educação híbrida. Revista Pátio, v. 17, n. 25 , p. $45-47,2015$.

abordagem teórico-prática. Porto Alegre: Penso, 2018.

BEHRENS, M. O paradigma emergente e a prática pedagógica. $6^{\mathrm{a}}$ ed. Petrópolis: Vozes, 2013.

EBELING, F.; BOHADA, E. O Facebook no Ensino Superior: transgressão e transformação. In. ROSADO, L. A.; BOHADA, E.; FERREIRA, G. (Orgs.) Educação e Tecnologia: parcerias 2.0. Rio de Janeiro: Ed. Universidade Estácio de Sá, 2013.

GABRIEL, Martha. Educar. A (r)evolução digital na educação. São Paulo: Saraiva, 2013. 
JONES, Vicki; JO, Jun H. Ubiquitous learning environment: An adaptive teaching system using ubiquitous technology. In: Beyond the comfort zone: Proceedings of the 21 st ASCILITE Conference. 2004. p. 474.

MODESTO, Marcelo. Uso das redes sociais na educação avança, mas ainda apresenta grandes desafios. 20 de abril de 2011. Disponível em https://www.institutoclaro.org.br/em-pauta/uso-dasredes-sociais-na-educacao-avanca-mas-ainda-apresenta-grandes-desafios/ > Acesso em 27/02/2016.

MORAES, M.C. Complexidade e Transdisciplinaridade na Formação Docente. In: MORAES, M.C.; NAVAS, J.M. (orgs) Complexidade e Transdisciplinaridade em Educação: teoria e prática docente. Rio de Janeiro: Wak Ed., 2010. P. 175-205.

SANTAELLA, Lucia. Desafios da ubiquidade para a educação. 04 de abril de 2013. Disponível em: $<$ https://www.revistaensinosuperior.gr.unicamp.br/artigos/desafios-da-ubiquidade-paraa-educacao $>$ Acesso em 27/02/2016.

A aprendizagem ubíqua substitui a educação formal? Revista de Computação e Tecnologia da PUC-SP. v. 2 n. 1, p. 17-22, 2010.

2013.

Comunicação ubíqua: repercussões na cultura e na educação. São Paulo: Paulus,

SANTOS, A; SOMMERMAN, A. (orgs) Complexidade e Transdisciplinaridade: em busca da totalidade perdida. Conceitos e práticas na educação. Porto Alegre: Sulina, 2009.

SANTOS, E.; WEBER, A. Educação e cibercultura: aprendizagem ubíqua no currículo da disciplina didática. Revista Diálogo Educacional da Pontifícia Universidade Católica do Paraná, v.13, n. 38 p. 285-303. Curitiba, 2013.

TSUKAMOTO, N., FIALHO, N. e TORRES, P.L. A face educacional do Facebook. Um relato de experiência. In. PORTO, Cristiane, SANTOS, Edméia (Orgs.). Facebook e educação: publicar, curtir, compartilhar. Campina Grande: EDUEPB, 2014.

VALENTE, José Armando. Pesquisa, comunicação e aprendizagem com o computador. O papel do computador no processo ensino-aprendizagem. In: ALMEIDA, Maria Elizabeth; MORAN, José Manuel (Org.). Integração das Tecnologias na Educação. Brasília: Ministério da Educação/Seed, 2005.

Blended learning e as mudanças no ensino superior: a proposta da sala de aula invertida. Educar em Revista, Curitiba, Brasil, Edição Especial n. 4/2014, p. 79-97. Editora UFPR. VERGARA, Sylvia Constante. Projetos e relatórios de pesquisa em administração. $9^{a}$ ed. São Paulo: Atlas, 2007.

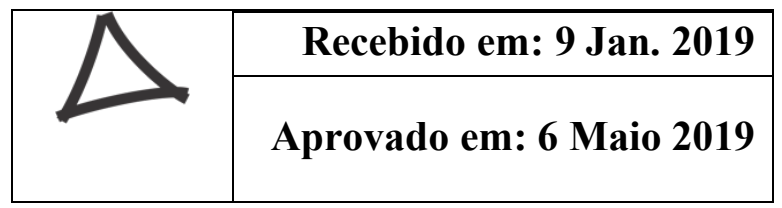

